\title{
Study of surface crystallinity and stoichiometry of laser annealed GaAs using time resolved reflectivity and channeling
}

\section{Citation}

Venkatesan, T. N. C., D. H. Auston, J. A. Golovchenko, and C. M. Surko. 1979. Study of Surface Crystallinity and Stoichiometry of Laser Annealed GaAs Using Time Resolved Reflectivity and Channeling. Appl. Phys. Lett. 35, no. 1: 88-90. doi:10.1063/1.31729.

\section{Published Version}

doi:10.1063/1.31729

\section{Permanent link}

http://nrs.harvard.edu/urn-3:HUL.InstRepos:29407061

\section{Terms of Use}

This article was downloaded from Harvard University's DASH repository, and is made available under the terms and conditions applicable to Other Posted Material, as set forth at http:// nrs.harvard.edu/urn-3:HUL.InstRepos:dash.current.terms-of-use\#LAA

\section{Share Your Story}

The Harvard community has made this article openly available.

Please share how this access benefits you. Submit a story.

\section{Accessibility}


Comparison of these results with a previously reported MIS structure ${ }^{17,18}$ suggests a reason for the failure of the present interface to give evidence of surface inversion in either high- or low-frequency $C-V$ data. That device employed a Langmuir film deposited at low temperature, and though the high-frequency capacitance appeared to fall below the capacitance at strong inversion due to leakage through the insulator, it did show evidence of surface inversion at low frequency $(30 \mathrm{~Hz})$. Though leakage in the present device is almost four orders of magnitude less than that for the Langmuir film, it invariably shows a slow rise in capacitance upon sweeping toward accumulation, and never the constant or high value of capacitance expected for high and low frequency, respectively. This difference between the two devices is unexpected, as the measured surface generation velocity is more than adequate to produce the hole currents needed in low-frequency $C-V$ experiments. Calculation also indicates bulk hole lifetime is comparable to that in the Langmuir film device, so hole recombination should not limit response.

Since hole generation and recombination both proceed rapidly, it appears frequency response of the present device in inversion is limited by interface-state capacitance. Interface trapping of holes at states distributed in energy would explain the absence of a clear dependence of inversion capacitance upon sweep rate and frequency. The importance of interface states in the present device is also indicated by the larger value of surface velocity. Comparison of the two devices suggests surface degradation caused by thermal treatment at $370^{\circ} \mathrm{C}$ introduces interface defects that trap carriers of either sign.
In conclusion, Zerbst and DLTS measurements indicate surface generation velocity for the present interfaces is $10^{4} \mathrm{~cm} / \mathrm{sec}$. Generation in the bulk occurs at a defect with a level near $E_{V}+0.5 \mathrm{eV}$, which has a cross section for electron emission at least $10^{8}$ times that for holes. In the present capacitors, minority charge near the interface is apparently trapped, thereby explaining the $C-V$ data observed under negative bias.

The authors gratefully acknowledge valuable discussions with Nelson Saks.

'L. Messick, J. Appl. Phys. 47, 4949 (1976).

${ }^{2}$ D.L. Lile and D.A. Collins, Thin Solid Films (to be published)

'L.G. Meiners, Thin Solids Films (to be published).

${ }^{4}$ D. Fritzche, Electron. Lett. 14, 51 (1978).

'C.R. Zeisse, L. Messick, and D.L. Lile, J. Vac. Sci. Technol. 14, 957

(1977).

${ }^{6}$ M. Zerbst, Z. Ang. Phys. 22, 30 (1966).

D.K. Schroder and J. Guldberg, Solid-State Electron. 14, 1285 (1971).

'D.V. Lang, J. Appl. Phys. 45, 3023 (1974).

${ }^{4}$ J.G. Simmons and G.W. Taylor, Solid-State Electron. 17, 125 (1974).

${ }^{10} \mathrm{~J}$. Stannard (unpublished).

"C.R. Bayliss and D.L. Kirk, J. Phys. D 9, 233 (1976)

${ }^{12}$ R.D. Burnham, N. Holonyak Jr., D.L. Keune, and D.R. Scifres, Appl. Phys. Lett. 18, 160 (1971)

"H.C. Casey and E. Buehler, Appl. Phys. Lett. 30, 247 (1977).

${ }^{14}$ C.A. Hoffman, K. Jarasiunas, and H.J. Gerritsen, Appl. Phys. Lett. 33, $536(1978)$

"W. Shockley and W.T. Read Jr., Phys. Rev. 87, 835 (1952).

${ }^{16} \mathrm{~A}$. Goetzberger, E. Klausmann, and M.J. Schulz, CRC Crit. Rev. Solid State Sci. 6, 1 (1976).

"G.G. Roberts, K.P. Pande, and W.A. Barlow, Electron. Lett. 13, 58 (1977)

${ }^{18}$ D.L. Lile, J. Vac. Sci. Technol. (to be published). Transconductance measurements also indicate Fermi level pinning.

\title{
Study of surface crystallinity and stoichiometry of laser-annealed GaAs using time-resolved reflectivity and channeling
}

T. N. C. Venkatesan

Bell Laboratories, Crawford Hill Laboratory, Holmdel, New Jersey 07733

\author{
D. H. Auston, J. A. Golovchenko, and C. M. Surko
}

Bell Laboratories, Murray Hill, New Jersey 07974

(Received 31 Jaunary 1979; accepted for publication 9 April 1979)

The surface crystallinity and stoichiometry of tellurium-implanted GaAs annealed with a frequency-doubled Nd:glass laser using time-resolved reflectivity and channeling measurements has been studied. By optimizing the duration of the liquid melt, depending on the implant dose, it has been possible to laser anneal implanted layers in uncapped GaAs with good surface crystallinity and minimal loss of arsenic due to surface decomposition. We propose a qualitative model of arsenic evaporation at the surface and subsequent replacement by arsenic displaced from the bulk by the tellurium which explains the dependence of the optimum melt duration on the dose of the implant.

PACS numbers: 79.20.Ds, 61.70. - r, 81.40.Ef

Recently, it has been shown that the application of intense laser beams to radiation-damaged ion-implanted semiconductors can have the beneficial effect of restoring crystal- linity to the host material with the substitutional incorporation of dopant atoms of interest. ${ }^{1}$ Most of this work has focused on the laser annealing of silicon where two 


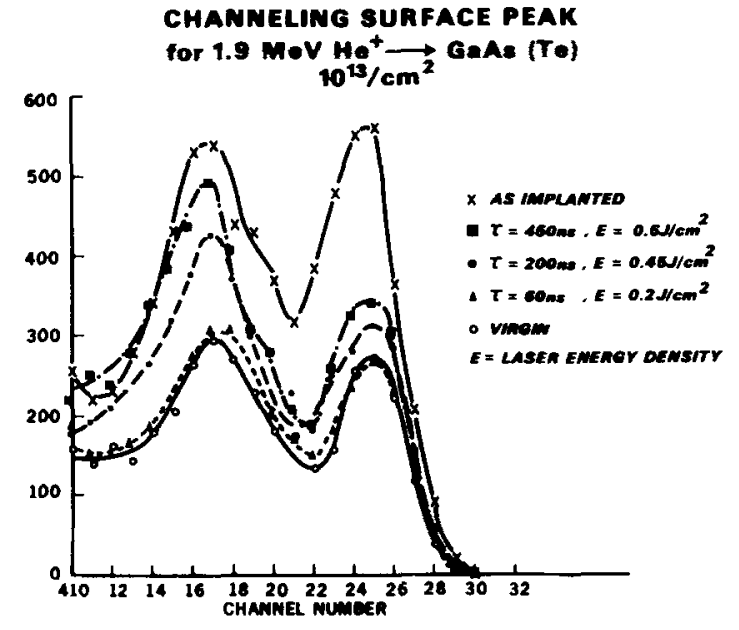

FIG. 1. Channeling spectrum showing As surface peaks for different melt durations for a low implant dose.

distinct annealing processes have been identified. One mechanism corresponds to an extension of conventional oven annealing and is commonly called "solid-phase" epitaxial regrowtn". ${ }^{2}$ In the second annealing regime a molten layer is formed near the surface, and the resultant "liquidphase epitaxial regrowth" from the undamaged underlayer upon cooling accounts for the annealing of the implanted layer. ${ }^{3}$ The role of the laser in both of these processes is to supply heat, or an optical absorption, in a highly localized manner near the sample surface for a short period of time. Scanning $\mathrm{cw}$ and $\mathrm{Q}$-switched lasers have mainly been used to effect the first and second aforementioned processes, respectively.

The conventional oven annealing of compound semiconductors such as GaAs has been complicated by the problem of significant evaporative loss of the more volatile component (in this case arsenic) at temperatures necessary for satisfory crystal regrowth. Various solutions to this problem such as hot implantation and "capped" oven annealing have been studied. ${ }^{4}$ The possibility of obtaining good single-crystal regrowth in uncapped GaAs using a $Q$-switched laser pulse has recently been demonstrated. ${ }^{5,6}$ Here, it had been anticipated that the short time available for annealing accounted for the lack of arsenic loss and hence successful results. More recently, the time-resolved reflectivity of the GaAs surface during the $Q$-switched annealing process has been measured ${ }^{7}$ and shown to generally correspond to the formation of a skin of the little studied metallic liquid phase of $\mathrm{GaAs}$ which can last up to several hundred nanoseconds, depending upon the annealing pulse energy.

In the following we show, through the use of Rutherford-backscattering channeling and time-resolved reflectivity studies, that a range of melt times does exist for which arsenic loss is minimal and crystalline recovery satisfactory, verifying the earlier anticipation. However, we also find that the annealing conditions for good crystalline regrowth depend upon implant dose and may be tailored to the case at hand.

Identical $\langle 100\rangle p$-type GaAs samples were implanted at room temperatures with doses of $10^{16}$ and $10^{13} \mathrm{Te} / \mathrm{cm}^{2}$ at
$50 \mathrm{keV}$. The tellurium projected range is approximately 200 $\AA$ with a straggle of $\sim 100 \AA$. The samples were then laser annealed while the surface reflectivity was monitored with a $\mathrm{He}-\mathrm{Ne}$ probe laser and a fast photodiode, as described in Refs. 3 and 7. Thus, each annealed spot on the wafer was characterized by the duration $\tau$ of the liquid layer at the sample surface. This is simply the duration of the enhanced reflectivity at a value consistent with the liquid metal. As in Refs. 3 and 7, we argue here that this time $\tau$ represents a most simple means of characterizing the annealing conditions. The annealing apparatus consisted of a $Q$-switched amplified Nd-glass laser operating in a single transverse mode followed by a KDP frequency doubler with a second-harmonic $(530 \mathrm{~nm})$ conversion efficiency of $\sim 15 \%$. The annealing pulse duration was $30 \mathrm{~ns}$ FWHM. The laser energy for various spots was varied from the threshold value for melting to the point where catastrophic surface damage appeared by changing the amplified pump level. As reported in Ref. 7, this energy range (i.e., $0.1-1 \mathrm{~J} / \mathrm{cm}^{2}$ ) resulted in melt times up to $\sim 600 \mathrm{~ns}$. A typical annealed spot was several $\mathrm{mm}$ in diameter. The threshold for annealing, i.e., single-crystal recovery as determined by a gross and sudden decrease in channeling-backscattering spectra, occurred at a melt time of $\simeq 50 \mathrm{~ns}$ in the $10^{16}-\mathrm{Te} / \mathrm{cm}^{2}$ sample. Anneals with melt times shorter than $50 \mathrm{~ns}$ appeared to recover to the eye insofar as the milky looking surface characteristic of the damaged layer disappeared. This recovery (of optical properties) undoubtedly represents polycrystalline regrowth near the surface not detectable by channeling. Single-crystal recovery is not achieved because for $\tau<50$ ns the melt does not penetrate to the undamaged crystal underlayer. By comparison, the $10^{13}-\mathrm{Te} / \mathrm{cm}^{2}$ sample annealed for liquid-layer duration at least as short as $20 \mathrm{~ns}$, although no recovery was observed for $\tau=0$. It should be noted that the highly doped sample is rendered completely amorphous by the implant and the low-dose sample is not.

In order to study the surface stoichiometry of annealed material we examined the channeling surface peaks in Rutherford-backscattering spectra for 1.9-MeV alpha particles aligned with the $\langle 100\rangle$ sample direction. Figure 1 shows

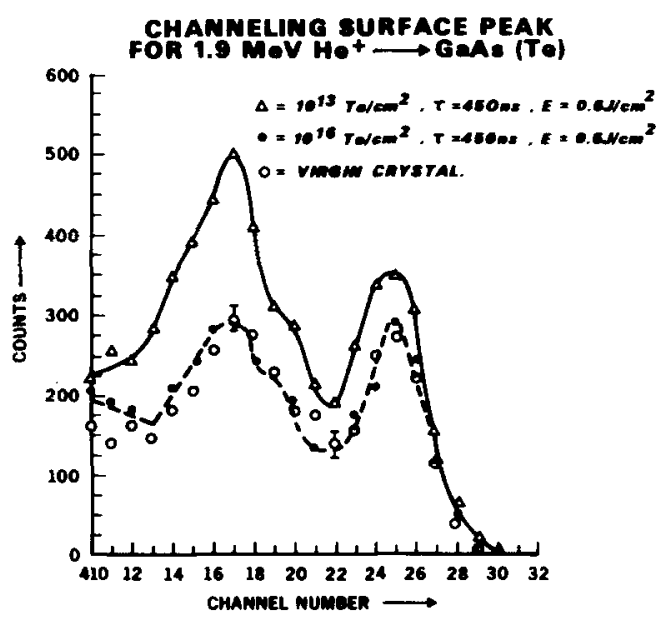

FIG. 2. Channeling spectrum showing $\mathrm{Ga}$ and As surface peaks at the same melt duration for two different implant doses. 
these results for differently treated spots on the $10^{13}$ $\mathrm{Te} / \mathrm{cm}^{2}$ sample. Each spectrum consists of two peaks. The one at lower energy (channel number) corresponds to gallium and the higher energy peak to arsenic. The strength of the peaks is, in part, controlled by the degree of disorder near the surface. This aspect of the interpretation is clearly demonstrated by a comparison of the results for an unimplanted (virgin) region with an implanted unannealed one. In order to interpret the remaining spectra in Fig. 1 it is necessary to recognize that the strength of a peak may also be diminished by the loss of material. Since the volatile material of concern here is arsenic we shall use the strength of the gallium peak as a measure of crystal disorder and the ratio of the arsenic-togallium peak as a measure of arsenic loss.

Referring to Fig. 1 again we note, for example, that the $\tau=60$ ns anneal yields essentially identical channeling results as virgin material. Also, the Te peaks showed good channeling dips analogous to those reported on in Ref. 5. However, for increasing values of $\tau$ the crystallinity deteriorates, as seen by the approach of the gallium peak toward the as-implanted level. The explanation for this degradation in crystallinity is also contained in the spectra, for it will be noted that the ratio of the arsenic-to-gallium peak strengths decreases with increasing $\tau$, indicating arsenic loss. From

Rutherford-backscattering cross sections we estimate a loss of $10^{16}$ arsenic atoms $/ \mathrm{cm}^{2}$ for the $\tau=450$-ns case. It would thus appear that if successful annealing of low-dose material is to be achieved, melt times of short duration are essential in order to avoid arsenic loss.

Curiously the situation is somewhat different for the high-dose sample. Figure 2 shows a comparison of $\tau=450$ ns anneals for the $10^{13}$ - and $10^{16}-\mathrm{Te} / \mathrm{cm}^{2}$ samples at about the same annealing energies along with the result from an unimplanted sample. The fact that the $\tau$ values are the same for both samples indicates that the molten layers lasted the same amount of time and therefore had the same thermal history. Clearly, the crystalline recovery for the high-dose sample is superior and compares favorably with unimplanted material. We believe that the evaporative arsenic loss of both the high- and low-dose implanted annealed samples is the same in this case. However, it is well known that the tellurium dopant replaces arsenic atoms when incorporated substitutionally in GaAs. The arsenic atoms thus freed by tellurium replacement during regrowth compensate nearly exactly for those lost by evaporation in the high-dose case and nearly perfect crystallinity results. It would thus appear that not only can arsenic loss be minimized through appropriate short liquid-melt laser annealing but it can be optimized to compensate for freed arsenic due to donor atom incorporation. Thus, by optimizing the duration of the liquid melt (depending on the implant dose), it should be possible to laser anneal implanted layers in uncapped $\mathrm{GaAs}$ with good surface crystallinity and minimal loss of arsenic.

Finally, we have observed recovery of optical properties of high-dose samples at laser energies below the threshold for formation of the liquid layer. Since the final reflectivity of the surface corresponded to that of crystalline GaAs (which is measured to be lower than the amorphous value by 15$40 \%$ ), but the channeling results have not been positive, we suspect a polycrystalline layer at the surface. This suggested a solid-phase recovery mechanism which needs further study.

We would like to acknowledge the timely help of W.R. Wagner is supplying us the GaAs wafers and J.F. Rodgers for the implantation.

'Phys. Today 31, 17-19 (1978) and references therein.

${ }^{2}$ A. Gat, F.J. Gibbons, T.J. Magee, J. Peng, V.R. Deline, P. Williams, and C.A. Evans, Appl. Phys. Lett. 32, 276 (1978); D.H. Auston, J.A. Golovchenko, P.R. Smith, C.M. Surko, and T.N.C. Venkatesan, Appl. Phys. Lett. 22, 539 (1978); J.S. Williams, W.L. Brown, H.J. Leamy, J.M. Poate, J.W. Rodgers, D. Rousseau, G.A. Rozgoyni, J.A. Shelnutt, and T.T. Sheng, Appl. Phys. Lett. 22, 539 (1978)

${ }^{3}$ D.H. Auston, C.M. Surko, T.N.C. Venkatesan, R.E. Slusher, and J.A. Golovchenko, Appl. Phys. Lett. 33, 437 (1978).

${ }^{4}$ F.H. Eisen, B.M. Welch, H. Muller, K. Gamo, T. Inada, and J.W. Mayer, Solid-State Electron. 20, 219-223 (1977); A. Lidow and J.F. Gibbons, Appl. Phys. Lett. 31, 158 (1977).

'J.A. Golovchenko and T.N.C. Venkatesan, Appl. Phys. Lett. 32, 147 (1978).

${ }^{6}$ G.A. Kachurin, N.B. Pridachin, and L.S. Smirnov, Sov. Phys.-Semicond. 9, 946 (1976); E. Rimini, P. Baeri, and G. Foti, Phys. Lett. A 65, 153 (1978); S.U. Campisano, I. Catalano, G. Foti, E. Rimini, F. Eisen, and M.A. Nicolet, Solid-State Electron. 21, 485 (1978); S.S. Kular, B.J. Sealy, K.G. Stephens, D.R. Chick, Q.V. Davis, and J. Edwards, Electron. Lett. 14, 85 (1978); B.J. Sealy, S.S. Kular, K.G. Stephens, R. Croft, and A. Palmer, Electron. Lett. 14, 720 (1978).

'D.H. Auston, J.A. Golovchenko, C.M. Surko, and T.N.C. Venkatesan (unpublished) 